\title{
UNIDADE DE TERAPIA INTENSIVA NEONATAL: PERCEPÇÕES MATERNAS SOBRE SÍMBOLOS RELIGIOSOS
}

\author{
Larissa Gramazio Soares ${ }^{1}$, Darci Aparecida Martins Correa ${ }^{2}$, Leticia Gramazio Soares ${ }^{3}$, leda Harumi Higarashi
}

${ }^{1}$ Enfermeira. Mestranda em Enfermagem. Docente de Enfermagem da Universidade Estadual do Paraná. Guarapuava, PR, Brasil. ${ }^{2}$ Enfermeira. Doutora em Ciências da Religião. Docente de Enfermagem da Universidade Estadual de Maringá. Maringá, PR, Brasil.

${ }^{3}$ Enfermeira. Doutoranda em Enfermagem. Docente de Enfermagem da Universidade Estadual do Centro-Oeste. Guarapuava, $\mathrm{PR}$, Brasil.

${ }^{4}$ Enfermeira. Doutora em Educação. Docente de Enfermagem (DEN) da Universidade Estadual de Maringá. Maringá, PR, Brasil.

RESUMO: Estudo de caráter descritivo, exploratório, de abordagem qualitativa, que pretendeu conhecer e compreender o significado que os símbolos religiosos têm para os pais de bebês internados na Unidade de Terapia Intensiva Neonatal e como estes os ajudam durante o período de internação do filho. A pesquisa de campo foi realizada em um hospital do Centro-Oeste do Paraná, no período de agosto a outubro de 2013, por meio de entrevistas semi-estruturadas com dez mães. Os dados foram analisados utilizando a técnica de análise de conteúdo, conforme Bardin, originando duas categorias temáticas. Conclui-se que, entre os diversos aspectos que permeiam o cenário da atenção intensiva neonatal e merecem ser reconhecidos e considerados pela equipe multiprofissional, em especial pela enfermagem, está a religiosidade. Esta constitui uma necessidade da família para o enfrentamento do agravo de saúde, demandando a realização de um cuidado espiritual com vistas à assistência integral e qualificada.

DESCRITORES: Enfermagem familiar; Religião; Unidades de terapia intensiva neonatal.

\section{NEONATAL INTENSIVE CARE UNIT: MATERNAL PERCEPTIONS ABOUT RELIGIOUS SYMBOLS}

ABSTRACT: A descriptive and exploratory study with a
qualitative approach was conducted with the aim to
understand the meaning of religious symbols for parents
of babies in the Neonatal Intensive Care Unit and how they
help them during the child's hospital stay. Field research
was carried out in a hospital in the Midwest of Paraná, from
August to October 2013, through semi-structured interviews
with ten mothers. Data were analyzed through content
analysis, according to Bardin, resulting in two thematic
categories. Religiosity is found to be among the various
aspects that permeate the scenario of neonatal intensive
care and deserve to be recognized and considered by the
multidisciplinary team, especially the nursing team. It is a
family need to cope with the health problem, demanding
spiritual assistance for comprehensive and quality care. DESCRIPTORS: Family nursing; Religion; Neonatal intensive care unit.

\section{UNIDAD DE TERAPIA INTENSIVA NEONATAL: PERCEPCIONES MATERNAS ACERCA DE SÍMBOLOS RELIGIOSOS}

RESUMEN: Estudio de carácter descriptivo, exploratorio, de abordaje cualitativo, cuyo objetivo fue conocer y comprender el significado que los símbolos religiosos tienen para los padres de bebés internados en la Unidad de Terapia Intensiva Neonatal y cómo estos los ayudan durante el periodo de internación del hijo. La investigación de campo fue realizada en un hospital del Centro-Oeste de Paraná, en el periodo de agosto a octubre de 2013, por medio de entrevistas semi estructuradas con diez madres. Los datos fueron analizados utilizando la técnica de análisis de contenido, de acuerdo a Bardin, originando dos categorías temáticas. Se concluye que, entre los diversos aspectos que permean el campo de la atención intensiva neonatal y merecen ser reconocidos y considerados por el equipo multiprofesional, en especial por la enfermería, está la religiosidad. Esta constituye una necesidad de la familia para el afrontamiento del agravio de salud, demandando la realización de un cuidado espiritual para llegar a una asistencia integral y cualificada.

DESCRIPTORES: Enfermería familiar; Religión; Unidades de terapia intensiva neonatal. 


\section{INTRODUÇÃO}

$\mathrm{O}$ internamento do recém-nascido na Unidade de Terapia Intensiva Neonatal (UTIN) é uma experiência difícil e dolorosa para os pais. Não raramente, os recursos e estratégias de apoio disponíveis nesta realidade são restritos, dificultando o seu processo de enfrentamento. Esse processo é permeado de ansiedades e expectativas, sobretudo, quanto ao diagnóstico e tempo de permanência, pois quanto mais longa a internação, maior se configura a ameaça à integridade do bebê, em função da predisposição à infecção e demais complicações clínicas ${ }^{(1-3)}$.

Diante deste cenário, os pais procuram estratégias que os ajudem a enfrentar este período de medo, sofrimento e angústia. Dentre estes recursos, a religiosidade e a espiritualidade aparecem de forma bastante importante, como elementos de suporte familiar neste momento difícil.

A religiosidade e a espiritualidade se destacam como uma das formas mais utilizadas pela população para expressar e enfrentar todos os sentimentos advindos do adoecimento. Diante de momentos de doença ou perda do ente querido, é notável o apelo à religião por parte dos familiares, através de promessas e orações que servem como fonte de esperança na sobrevivência do doente e como forma de suportar a situação ${ }^{(4)}$.

O sagrado, enquanto realidade transcendente, mostra ao ser humano refletido em um objeto ou uma pessoa de sacralidade, uma possibilidade de comunicar-se com o transcendente, com o Sagrado. Esta ponte ou via de conexão pode tornar-se visível e palpável, sendo considerado pelas pessoas como o símbolo materializado do divino. Nesta perspectiva, o símbolo religioso está localizado, em primeiro lugar, "entre" o totalmente Outro e o sujeito humano que o experimenta ${ }^{(5)}$. Da mesma forma "o símbolo, o mito e o rito são as primeiras manifestações, as mais espontâneas, da vivência do encontro humano com o Absoluto" (5:397).

Tais considerações acerca da importância dos símbolos na relação do ser humano com o sagrado, devem ser percebidas e valorizadas no ambiente da UTIN, sempre que os pais expressarem a necessidade de recorrerem a estes símbolos religiosos.

Em face de tais considerações, a presente pesquisa se justifica no sentido de (re)conhecer o significado atribuído aos símbolos religiosos que os pais dos recém-nascidos internados em UTIN utilizam para o enfrentamento da hospitalização de neonatos em UTIN. Tal conhecimento implica em valorizar o cuidado de enfermagem humanizado e integral, considerando atender o indivíduo em todas as suas necessidades, inclusive a necessidade espiritual, que ainda é pouco explorada e pesquisada.

Nesse sentido, este estudo teve como objetivo conhecer e compreender o significado que os símbolos religiosos têm para os pais de bebês internados na UTIN e como estes símbolos os ajudam durante o período de internação de seu filho.

\section{MÉTODO}

A opção pelo estudo descritivo, exploratório com abordagem qualitativa, se deu em função desta abordagem propiciar a interação entre pesquisador e sujeitos da pesquisa, necessária ao alcance do objetivo estabelecido de conhecer o significado que os símbolos religiosos têm para os pais no processo de enfrentamento na hospitalização do seu filho na UTIN.

A pesquisa foi realizada na UTIN de um hospital de pequeno porte, na cidade de Guarapuava, no interior Paraná, Brasil. Trata-se de uma entidade filantrópica, fundada em 1913 e que conta atualmente com 154 leitos. A UTIN, locus de realização do estudo, foi inaugurada em outubro de 2012 e dispõe atualmente de 07 leitos neonatais. O referido serviço conta com uma equipe multidisciplinar, composta por quatro enfermeiras, nove técnicos de enfermagem, seis médicos, uma fisioterapeuta, uma nutricionista, uma fonoaudióloga e uma psicóloga.

O critério único de inclusão foi o de ser mãe de neonato com tempo de internação igual ou superior a 15 dias. Tal período de permanência se justifica em razão da necessidade de que os sujeitos participantes tivessem uma vivência mínima no contexto a ser pesquisado.

Em relação ao número de participantes, um estudo de cunho qualitativo não se preocupa com critérios numéricos, pois valoriza mais a compreensão ampla e densa sobre grupos determinados. Nos estudos qualitativos, a amostra é constituída por sujeitos sociais que possuem as informações que respondem à indagação do pesquisador $^{(6)}$. A observância destes aspectos resultou na realização de dez entrevistas.

Os dados foram coletados no período 
de agosto a outubro de 2013, por meio de entrevistas gravadas, utilizando-se de um roteiro semi-estruturado, composto de uma seção para a caracterização sociodemográfica das participantes, e outra contendo a questão norteadora.

As entrevistas foram realizadas sem ambiente privativo no próprio Hospital, conforme preferência das mães e após o horário de visitas. Posteriormente, os registros em áudio foram transcritos na íntegra e submetidos a sucessivas leituras.

Para a análise dos dados, utilizou-se a técnica de análise de conteúdo ${ }^{(7)}$, seguindo as seguintes fases: pré-análise, exploração do material, análise e interpretação referencial. Deste processo emergiram duas categorias centrais e seis subcategorias, que compõe o corpus para a discussão do estudo.

A pesquisa foi realizada de acordo com os preceitos éticos, e a coleta de dados se deu somente após análise e aprovação do projeto de pesquisa pelo Comitê Permanente de Ética em Pesquisa Envolvendo Seres Humanos da Universidade Estadual de Maringá, conforme parecer $n^{\circ} 370.185$. A fim de garantir o anonimato dos sujeitos, foram atribuídos nomes fictícios às mães participantes da pesquisa.

\section{RESULTADOS}

Para a caracterização das entrevistadas, foram levantados dados relativos à mãe, bem como aspectos relacionados à hospitalização do bebê internado. O levantamento de tais aspectos objetivou contextualizar a realidade subjetiva das participantes, de forma a orientar a análise individualizada dos relatos.

\section{Caracterização dos participantes e hospitalização}

O universo de estudo foi composto por mães dos recém-nascidos (RN) internados na UTIN, totalizando dez entrevistadas. A faixa etária das participantes variou de dezoito a quarenta e quatro anos, sete delas residiam na cidade de Guarapuava e as demais, em cidades circunvizinhas. Com relação à escolaridade, cinco possuíam ensino fundamental completo e as demais haviam integralizado o ensino médio. A renda mensal da família variou entre $\mathrm{R} \$ 350,00$ e $\mathrm{R} \$$ 2.034,00; no que diz respeito ao estado civil, cinco apresentavam-se casadas e as demais solteiras ou divorciadas; quanto à profissão, cinco eram "donas de casa" e as demais profissões incluíram: duas como cozinheira, duas eram autônomas e uma funcionária pública. Ao serem questionadas a respeito da religião, oito referiram ser católicas e duas evangélicas.

Com relação ao tipo de parto, a distribuição entre cesáreas e partos normais foi equitativa, com cinco partos de cada tipo e registro de dois partos gemelares, totalizando 12 recémnascidos internados, sendo três do sexo masculino e nove do sexo feminino. Quanto ao tempo de hospitalização, seis RN estavam internados há mais de 30 dias. Os motivos de internação variaram, incluindo: baixo peso ao nascer, insuficiência respiratória, cardiopatia e infecção neonatal. A justificativa mais frequente de internação foi prematuridade, verificado em 09 internamentos, sendo que a idade gestacional dos bebês, esta variou entre 28 e 37 semanas de gestação, e peso ao nascer oscilando entre $945 \mathrm{~g}$ e $3.900 \mathrm{~kg}$. Apenas um RN apresentou peso de nascimento adequado.

Com relação à abordagem da temática central do estudo, do processo de análise dos relatos obtidos a partir da questão norteadora "Vocês fazem uso de símbolos religiosos para o enfrentamento da hospitalização do seu filho na UTIN e como esses símbolos os ajudam nessa situação?", depreenderam-se duas categorias temáticas: Símbolos religiosos; e Importância e influência dos símbolos religiosos no processo de recuperação do $\mathrm{RN}$ enfermo. As subcategorias que compõem, juntamente com as categorias temáticas centrais, o corpus do processo analítico, serão apresentadas a seguir.

\section{Símbolos Religiosos}

O ser humano busca respostas para o desconhecido. Quando não encontra, atribui a uma característica divina, uma origem transcendente e misteriosa, à qual não cabe responder questionamentos humanos. Os símbolos religiosos surgem nesse contexto, como a representação da crença no superior, no sagrado.

Assim, há que se destacar que símbolo é um elemento representativo (realidade visível) que está em lugar de algo (realidade invisível), podendo ser um objeto ou ideia. O símbolo é um elemento essencial no processo de comunicação, encontrando-se difundido pelo cotidiano e pelas mais variadas vertentes do saber humano. Embora existam símbolos que são reconhecidos internacionalmente, outros só são compreendidos dentro de um determinado 
grupo ou contexto religioso, intensificando a relação com o transcendente, com o sagrado.

Vários foram os símbolos religiosos citados pelas mães. Entretanto, optou-se por delimitar a discussão em torno daqueles que mais apareceram nos depoimentos, quais sejam: as imagens de santos, o terço e a Bíblia.

\section{Imagens de Santo}

Muitos santos foram apontados pelas mães como símbolos religiosos, dentre estes, os mais citados foram: Nossa Senhora Aparecida; Nossa Senhora das Graças; Nossa Senhora do Parto e Santa Rita de Cássia.

Eu ganhei a medalhinha de Nossa Senhora das Graças da vó do meu nenêl...]para que, sempre que eu entrasse lá na UTI, colocasse na mãozinha dele pra que ele tivesse força; pra que ele reagisse e logo saísse. Pelo jeito tem dado certo, eu coloco na mão dele e na hora de sair eu tiro e levo comigo[...]. (PAULA)

Eu tenho essa medalhinha de Santa Rita de Cássia que carrego sempre comigo [...] símbolos são as coisas de Deus [...] ganhei da minha mãe que é devota [...]. (SANDRA)

Tais relatos expressaram o apego ao simbolismo divino com esperança da melhora clínica do filho, essas mães depositam suas expectativas de recuperação nas imagens santas referidas.

\section{O Terço}

Considerando que o homem é dotado da necessidade de símbolos para aproximá-lo do real, os acontecimentos religiosos se utilizam de símbolos para aproximação com o Sagrado. O mesmo símbolo pode ter diferentes significados de acordo com as variedades culturais existentes. Nesse sentido, outro símbolo religioso que as mães citaram foi o terço, sempre presente nas visitas destas à UTIN.

Eu sempre carrego comigo um tercinho[...] eu ganhei, veio lá de Aparecida, veio benzido de lá, cada vez que eu venho aqui, eu fico pegando nele dentro do bolso da blusa, ficava com ele[...]. (ANA)

Eu levo o tercinho no bolso, em toda visita e quando estou do lado dela, aperto forte nele e entrego ela nas mãos do Nosso Senhor Jesus Cristo, eu sinto que Ele esta lá, perto deles[...].(CAROLINA)

Os relatos atribuíam a este símbolo o poder de propiciar força para o enfrentamento da situação de dor, angústia e medo de perder o filho. Vale ressaltar também a necessidade do toque e apego ao símbolo, como forma de materialização do Sagrado.

\section{A Bíblia}

Outro símbolo importante para as mães do estudo como fonte de auxílio foi a Bíblia. Este auxílio se apoiava nas promessas de cura nela presentes, fortalecendo assim as esperanças na recuperação de seus filhos, como expressado nas falas a seguir:

Eu leio muito a bíblia, eu entendo que ela é como um manual da vida, que a gente tem que seguir, a palavra é tudo na vida da gente. Não a bíblia, sabe? A palavra que está nela que é o mais importante para a gente, todos os ensinamentos [...]. (MARIA)

Para nós só existe o poder da oração e a bíblia/a palavra, a fé e a oração são tudo na vida de um evangélico, representa a força. (DENISE)

Para estas mães, a leitura da Bíblia representava uma estratégia para o enfrentamento da situação adversa vivenciada naquele momento.

\section{Importância e influência dos símbolos religiosos no processo de recuperação do $\mathrm{RN}$ enfermo}

Na busca pela religiosidade em circunstâncias de dor e sofrimento, o ser humano, na tentativa de aproximar-se de Deus e do Sagrado, acaba muitas vezes lançando mão dos símbolos religiosos. O mesmo símbolo pode ter diferentes significados e mobilizar diversas ações na vida das pessoas.

Nesse estudo, os símbolos religiosos assumiram diferentes significados e papéis para as mães, destacando-se a fé, a força e a segurança para suportarem e vivenciarem a hospitalização de seus filhos.

\section{A Fé}

Segundo a perspectiva de algumas entrevistadas, o bom prognóstico e a recuperação de seus bebês eram resultantes de toda a fé depositada em Deus. Em seus discursos, estas revelam acreditar que se não tivessem rezado, o quadro clínico de seus filhos poderia ter tido outro desfecho:

Sem a oração, sem ter me apegado cada vez mais a Deus, não teria conseguido nada de bom, todo o resultado que eu estou tendo agora, é por isso, é através disso. (ANA)

Foi importante ter rezado porque ela ficou bem [...] isso ajudou, ajudou ela a ficar bem e tudo, ela tá bem até agora. (ISABEL) 
Dessa forma, os relatos das entrevistadas no presente estudo evidenciaram que as orações e a fé passaram a ter maior significado após a experiência da hospitalização. Deste modo, diante da situação de sofrimento e adoecimento vivenciada, as mães passaram a valorizar as práticas religiosas como estratégia pessoal de enfrentamento e fortalecimento.

Não que eu não acreditasse, mas eu não dava importância, hoje eu dou mais importância [...] me trouxe mais próxima a Deus. (ANA)

A gente sempre diz que acredita e reza, mas agora passou a ter mais força, a ser mais que antes, a gente peca nisso, porque eu estou sofrendo muito daí na fé eu me fortaleço. (FLAVIA)

Portanto, verificamos que a própria hospitalização do filho é atribuída por parte das mães, à providência divina, como acontecimento inevitável e necessário. Assim, como forma de amenizar as angústias decorrentes deste processo, as mães parecem se fortalecer ao buscar um significado para o fato vivenciado, tendo como premissa a existência de um propósito transcendental para a situação enfrentada, como apresentado nas falas de Ana e Carolina:

Eu acho que isso é uma lição de vida, tudo que você passa tem um significado, tudo que você passa, ninguém poderia ter passado no meu lugar [...]. (ANA)

Provação é isso que eu sinto, Deus sabe de tudo, se era para a vida da Eloise começar assim, vamos enfrentar e ter fé, desistir nunca, perder a fé nunca, nunca[...]. (CAROLINA)

\section{Força}

Ainda no que se referem aos símbolos religiosos, os relatos maternos destacaram como estes sendo fonte de força nesse momento da hospitalização do filho. Além disso, as práticas religiosas serviram como estimulante espiritual para que as mães permanecessem fortes, com vistas a atender seus filhos quando estes necessitassem.

Minhas orações eu fazia sempre [...] ajudaram a mim, se eu me entregasse, agora eu não poderia estar cuidando dele [...] eu pensava assim, eu tenho que ter força, pedia a Deus pra eu poder ficar forte pra amamentar e ele ficar bom, como eu vou amamentar ele se eu ficar nervosa... me ajudou bastante[...].(ANA)

A gente sempre reza e tem fé, mais quando acontece alguma coisa a gente se apega mais, pra ter força e aguentar[...] agora eu vejo a força que teve minhas orações, ela ajudou muito ela a se recuperar e ter força [...].(SUZANA)

Deste modo, o apego maior à religiosidade, motivado pela situação de sofrimento e tristeza, foi considerado como ponto de partida para que as mães encontrassem força para se manterem otimistas e confiantes em relação ao bom prognóstico do filho e estarem fortalecidas no momento em que os filhos necessitassem.

\section{Segurança}

Por fim, os discursos maternos evidenciaram que os sentimentos negativos advindos da hospitalização do filho são amenizados quando estas "entregam" o filho a Deus. Nesse sentido, as mães comumente colocavam terços e imagens (fotos) de santos nas incubadoras. Para elas, além da equipe de saúde e da tecnologia de suporte de vida presente nesse contexto, Deus se fazia presente por meio dos símbolos que deixavam no leito de seus filhos, sendo estes símbolos um fator de proteção, aumentando a sensação de segurança em relação aos cuidados ali executados:

Eu saio de lá da UTI, eu sinto que Ele fica lá cuidando dela, guiando os médicos e as enfermeiras, eu sinto isso [...] entreguei ela nas mãos de Deus, eu vejo que Ele está lá com ela e vai proteger porque ela é um anjinho[...]. (FLAVIA)

Deus, Nossa Senhora Aparecida e os anjinhos estão lá, as mãos deles a guardam, está guiando as pessoas que cuidam, a proteção maior vem de Deus, porque não adianta só os remédios e os aparelhos, a oração e a fé também curam [...] quando eu saio de lá eu sinto a presença de Deus naquele lugar, isso já me ajuda [...] eu vejo ele lá do lado da incubadora [...].(CAROLINA)

Embora tais conceitos ainda não sejam adequadamente disseminados nas realidades assistenciais de nosso país, é possível verificar a presença dos símbolos religiosos no cotidiano das internações neonatais, enquanto recursos de enfrentamento utilizados pelas famílias diante dos momentos de tristeza e angústia vivenciados junto a seus filhos, devendo ser reconhecidos e valorizados pela equipe que presta assistência ao binômio mãe-filho.

\section{DISCUSSÃO}

A literatura faz referência à importância dos símbolos na relação do ser humano com o sagrado, e estes são percebidos com relevância 
nas narrativas das entrevistadas, pela profunda valorização atribuída por elas aos símbolos no momento da experiência religiosa. Percebe-se ainda que cada mãe revelou uma experiência humana singular com determinados símbolos, e que estes a ajudam na sua proximidade com o Sagrado ${ }^{(5)}$.

Sendo assim, a religião é expressa através dos símbolos religiosos e traduz o irracional, e possui raízes tão profundas na alma humana, que o ser ao vivenciar um momento de fragilidade e vulnerabilidade apega-se a eles ${ }^{(8)}$, como evidenciado nas falas das mães.

Nesta mesma perspectiva, as famílias utilizaram recursos religiosos para buscar entender e lidar com situações de adoecimento, bem como para enfrentar momentos de fragilidade decorrentes da enfermidade. A literatura ratifica as orações, promessas, peregrinações, exercícios ascéticos e ações rituais, como apego aos objetos conforme sua religião ${ }^{(9)}$.

Além disso, em uma pesquisa intitulada (10) "A expressão da dimensão espiritual no cuidado de Enfermagem em Unidade de Terapia Intensiva", os resultados corroboram com os aqui encontrados, uma vez que o autor apresentou símbolos religiosos como terços, santinhos e bíblia, enquanto veículos da fé dos participantes de sua pesquisa.

Nesta perspectiva ${ }^{(11)}$, religião é uma das "teias de significados" que compõem a cultura, que nada mais é que os sistemas de significados transmitidos historicamente e incorporados como símbolos, por meio dos quais os homens se comunicam, perpetuam e desenvolvem seu conhecimento e suas atividades em relação à vida. Sendo assim, estes sistemas complexos de símbolos representam fontes extrínsecas de informações importantes para o comportamento humano e servem para modelar as relações entre as entidades e os processos sociais. Dessa maneira, os mesmos sentimentos usados na devoção aos símbolos religiosos são utilizados para direcionar a vida, pois fornecem sentido de revelação e direção.

Corroborando com o exposto acima, os resultados da pesquisa evidenciam que diante do processo de hospitalização e de todo o sofrimento que essa experiência causa, o apego à religião foi uma alternativa utilizada a fim de amenizar os sentimentos negativos vivenciados nessa fase.

De modo geral, a religiosidade ocupa espaço importante na vida do ser humano e é capaz de ajudá-lo a encontrar respostas para diversas situações adversas, como é o caso das doenças. Esse encontro entre o ser humano e o Sagrado se estabelece no momento de necessidade, por meio da espiritualidade, como sendo "um encontro com Deus, um contato pessoal com Ele, reconhecimento humilde e devoto do Seu valor absoluto e da Sua santidade" (12:59).

Destacamos ainda, que a oração é utilizada pela família para estabelecer uma conexão com Deus ou com uma Entidade ou Força superior, reforçando sua fé. A melhora da criança é, deste modo, interpretada como um fato intimamente relacionado à força da oração e da fé(13).

Da mesma forma, em outro estudo(14), corroborando com os achados da pesquisa em questão, as práticas cotidianas religiosas implementadas por meio de orações proporcionaram tranquilidade, bem-estar e fortalecimento para a vida.

Essa experiência deu início a uma fase de reflexão e ressignificação da religião. As famílias que tiveram seus filhos internados em UTIN passam, assim, a se aproximarem mais da Igreja e dos rituais religiosos, no sentido de estabelecerem uma conexão pessoal com "Algo maior", e deste modo, serem amparadas nesse momento de dificuldade ${ }^{(14)}$.

Do mesmo modo, ainda que a fé e a religiosidade sempre se façam presentes na vida do ser humano, é principalmente em um momento de vulnerabilidade que se dá a retomada do Sagrado, enquanto estratégia pessoal de enfrentamento ${ }^{(15)}$.

Cabe destacar que no ambiente da UTIN, mesmo com os recursos tecnológicos atualmente disponíveis para a manutenção da vida do filho, o apego ao Sagrado proporciona sensação de conforto à família, fazendo com que esta busque na religiosidade significado para o seu sofrimento ${ }^{(15)}$.

Alguns autores estabelecem ainda que, uma situação adversa como a hospitalização de um filho na UTIN, conduz a família a buscar forças e a acreditar que só poderá enfrentar esse momento pela fé na existência de um Ser Superior, capaz de lhes conceder conforto, por meio da implementação de práticas de devoção ${ }^{(13)}$.

Estas impressões ratificam os achados de outro estudo $^{(16)}$, que buscou identificar os significados culturais que os clientes admitidos em Centro de Terapia Intensiva e seus familiares atribuíam ao processo de hospitalização, e que concluiu que 
as famílias fortalecem-se na fé e na presença de Deus. Para eles, a fé pode trazer a cura, aceitação dos fatos ocorridos e resignação, minimizando os efeitos estressores oriundos da internação, reconhecendo a fé como tendo efeito positivo nesse processo. As famílias do estudo também revelaram crer no poder de Deus na decisão sobre a vida e a morte.

Tais considerações corroboram a importância de se valorizar o cuidado integral, humanizado e de qualidade neste e em outros cenários assistenciais. É essencial que o enfermeiro perceba a necessidade espiritual expressa pela família dos bebês internados em UTIN. Para implementar o cuidar espiritual, faz-se mister compreender, relacionar-se, comunicar-se, interagir e estar com o outro. Destaca-se ainda que a enfermagem está caminhando para uma nova era - a era do cuidado terapêutico espiritualizado ${ }^{(17)}$.

Dessa forma, é necessário compreender o processo de enfrentamento da hospitalização do filho valorizando a subjetividade expressada pela família. Sendo assim os profissionais devem apoiá-las e identificar suas dificuldades além de desenvolver estratégias para fortalecer o vínculo com o bebê $\hat{e}^{(18)}$.

Nesse sentido a religiosidade é, assim, praticada de forma intensa, como forma de renovar as esperanças na recuperação plena do bebê, e de manter a família forte para o enfrentamento da hospitalização, e preparada para lidar com as necessidades do filho.

\section{CONSIDERAÇÕES FINAIS}

A presente pesquisa se insere, essencialmente, nas áreas da Espiritualidade e Religiosidade, com o objetivo de conhecer e compreender a partir desta perspectiva o significado que os símbolos religiosos têm para os pais de bebês internados na UTIN e entender como estes os ajudam durante o período de internamento de seu filho.

Refletir sobre a religiosidade e reconhecêla como uma necessidade também da família, inserida no contexto da assistência de enfermagem em uma UTIN, é de grande importância. A família que enfrenta o processo de hospitalização do seu filho passa por constantes situações de dificuldade, permeadas por abalos emocionais, vivências espirituais, e o temor da finitude. Logo, sua percepção sobre a religiosidade é rica e relevante, justificando a realização deste estudo.

O apego aos símbolos religiosos neste contexto de enfrentamento ficou evidente em todos os relatos do estudo. Assim, os símbolos religiosos foram percebidos pelas mães como um caminho para a aproximação com o Sagrado, e como estratégia para se fortalecerem no processo de enfrentamento da hospitalização do filho.

Os símbolos propiciavam ainda o aumento da fé, por meio da reflexão e da ressignificação da religiosidade nas vidas destas famílias. De tal processo reflexivo, as famílias concluíram pela reafirmação de suas práticas religiosas, e pelo fortalecimento de sua crença acerca de uma determinação divina dos eventos.

Os resultados apontaram também a força e a segurança proporcionadas pelos símbolos, que motivam as mães para o otimismo quanto à evolução de seus filhos, bem como as deixam mais confiantes e seguras no enfrentamento da situação.

A essência do cuidado de enfermagem está em atender todas as necessidades do paciente e sua família, com vistas a promover uma assistência integral e qualificada. Nesse sentido, sugere-se que a temática da espiritualidade e do cuidado espiritual seja melhor explorada no processo formativo dos profissionais, de maneira a tornálos mais sensíveis e capazes de perceber a necessidade espiritual, reconhecendo a família como foco do cuidado.

\section{REFERÊNCIAS}

1. Roecker S, Mai LD, Baggio SC, Mazzola JC, Marcon SS. Demandas assistenciais frente à gestação e o nascimento de bebês com malformação. Rev. enferm. UFSM. [Internet] 2012; 2(2) [acesso em 20 out 2013]. Disponível: http://cascavel.ufsm.br/revistas/ojs-2.2.2/ index.php/reufsm/article/view/4614.

2. Cruz ARM, Oliveira MMC, Cardoso MVLML, Lúcio IML. Sentimentos e expectativas da mãe com filho prematuro em ventilação mecânica. Rev. Eletr. Enf. [Internet] 2010; 12(1) [acesso em 20 out 2013]. Disponível: https://www.fen.ufg.br/fen_revista/v12/n1/ pdf/v12n1a16.pdf.

3. Rosenzvaig AMV. Conversa de UTI: grupo de pais num serviço de UTI neonatal. J. psicanal. [Internet] 2010; 43(79) [acesso em 20 out 2013]. Disponível: http://pepsic.bvsalud.org/scielo.php?script=sci_ arttext\&pid=S0103-58352010000200011\&lng=pt\&nrm =iso.

4. Véras RM, Vieira JMF, Morais FRR. A maternidade prematura: o suporte emocional através da fé e religiosidade. Psicol. estud. [Internet] 2010; 15(2) [acesso em 20 out 2013]. Disponível:http://dx.doi. 
org/10.1590/S1413-73722010000200011.

5. Croatto JS. As linguagens da experiência religiosa: uma introdução à fenomenologia da religião. São Paulo: Edições Paulinas; 2001.

6. Minayo MCS. O desafio do conhecimento: pesquisa qualitativa em saúde. 14ª ed. São Paulo: Hucitec; 2014.

7. Bardin L. Análise de conteúdo. Tradução de Luís Antero Reto e Augusto Pinheiro. São Paulo: Edições 70; 2011.

8. Rodrigues MH. A queda do simbólico na vida contemporânea: uma interpretação da relação dos sujeitos com os símbolos da igreja matriz de americana. Rev. Último andar. [Internet] 2013; (21) [acesso em 20 out 2013]. Disponível: http://revistas.pucsp.br/index. php/ultimoandar/article/view/13987/10293.

9. Paiva GJ. Religião, enfrentamento e cura: perspectivas psicológicas. Estud. psicol. [Internet] 2007; 24(1) [acesso em 20 out 2013]. Disponível:http:// dx.doi.org/10.1590/S0103-166X2007000100011.

10. Penha RM. A expressão da dimensão espiritual no cuidado de Enfermagem em Unidade de Terapia Intensiva [dissertação]. São Paulo (SP): Universidade de São Paulo, Escola de Enfermagem; 2008.

11. Geertz C. A interpretação das culturas. Rio de Janeiro: Editora LTC; 1989.

12. Mondin B. O Homem: quem ele é?:elementos de antropologia filosófica. São Paulo: Editora Paulus; 1980.

13. Bousso RS, Serafim TS, Misko MD. A relação entre religião, doença e morte em histórias de vida de familiares de crianças com doenças potencialmente fatais. Rev. Latino-Am. Enfermagem. [Internet] 2010; 18(2) [acesso em 20 out 2013]. Disponível:http://dx.doi. org/10.1590/S0104-11692010000200003.

14. Dezorzi LW, Crossetti MGO. Spirituality in selfcare for intensive care nursing professionals.Rev. Latino-Am. Enfermagem. [Internet] 2008; 16(2)[acesso em 20 out 2013]. Disponível: http://dx.doi.org/10.1590/ S0104-11692008000200007.

15. Corrêa DAM. O Cuidado Espiritual na enfermagem. In: Costenaro RGS, Lacerda MR. Quem cuida de quem cuida? Quem cuida do cuidador? As teias de possibilidades de quem cuida. $3^{\mathrm{a}}$ ed. Porto Alegre/RS: Editora Moriá; 2013. p.39-41.

16. Lemos RCA, Rossi LA. O significado cultural atribuído ao Centro de Terapia Intensiva por seus Clientes e Familiares: um elo entre a beira do abismo ea liberdade. Rev. Latino-Am. Enfermagem. [Internet] 2002; 10(3) [acesso em 20 out 2013]. Disponível: http:// dx.doi.org/10.1590/S0104-11692002000300009.
17. Manenti LP, Soratto MT. A importância da espiritualidade no cuidado com o paciente internado na UTI Cardiovascular. Saúde Rev. [Internet] 2012; 12(30) [acesso em 20 out 2013]. Disponível: https:// www.metodista.br/revistas/revistas-unimep/index. php/saude/article/view/1030/535.

18. Tronco CS, Padoin SMM, Paula CC, Rodrigues AP, Terra MG, Aldrighi JD. "Não esperava que nascesse antes" - vivência materna diante da internação na unidade de terapia intensiva neonatal. Cogitare Enferm. 2015; 20(1)[acesso em 18 mai 2015]. Disponível: http://dx.doi.org/10.5380/ce.v20i1.38141. 